IZA DP No. 9607

Capital Income Taxation and Household Production

Patricia Apps

Ray Rees

December 2015

Forschungsinstitut zur Zukunft der Arbeit Institute for the Study of Labor 


\title{
Capital Income Taxation and Household Production
}

\author{
Patricia Apps \\ Sydney University Law School \\ and IZA \\ Ray Rees \\ University of Munich, \\ University of Oslo and Sydney University Law School
}

\section{Discussion Paper No. 9607 December 2015}

\author{
IZA \\ P.O. Box 7240 \\ 53072 Bonn \\ Germany \\ Phone: +49-228-3894-0 \\ Fax: +49-228-3894-180 \\ E-mail: iza@iza.org
}

\begin{abstract}
Any opinions expressed here are those of the author(s) and not those of IZA. Research published in this series may include views on policy, but the institute itself takes no institutional policy positions. The IZA research network is committed to the IZA Guiding Principles of Research Integrity.

The Institute for the Study of Labor (IZA) in Bonn is a local and virtual international research center and a place of communication between science, politics and business. IZA is an independent nonprofit organization supported by Deutsche Post Foundation. The center is associated with the University of Bonn and offers a stimulating research environment through its international network, workshops and conferences, data service, project support, research visits and doctoral program. IZA engages in (i) original and internationally competitive research in all fields of labor economics, (ii) development of policy concepts, and (iii) dissemination of research results and concepts to the interested public.
\end{abstract}

IZA Discussion Papers often represent preliminary work and are circulated to encourage discussion. Citation of such a paper should account for its provisional character. A revised version may be available directly from the author. 
IZA Discussion Paper No. 9607

December 2015

\section{ABSTRACT \\ Capital Income Taxation and Household Production*}

The Atkinson-Stiglitz Theorem and its extensions have been interpreted as implying that capital income should not be taxed. If, as seems reasonable on empirical grounds, we introduce production of household goods with close market substitutes, this conclusion no longer holds. We analyse optimal capital income taxation for this case.

JEL Classification: H22, D13

Keywords: optimal capital taxation, household production

Corresponding author:

Patricia Apps

Faculty of Law

University of Sydney

NSW 2006

Australia

E-mail: patricia.apps@sydney.edu.au

\footnotetext{
* We are grateful to Robin Boadway for helpful notes and comments. The research was supported under the Australian Research Council's Discovery Project funding scheme (Project ID: DP120104115).
} 


\section{Introduction}

In a standard model of the intertemporal labour supply/consumption/saving decision, with weak separability between consumption and leisure in each period, identical preferences across households and a Mirrlees optimal nonlinear tax on labour earnings, the Atkinson-Stiglitz Theorem ${ }^{1}$ implies that there is no case for taxing future consumption and therefore the return to saving. An extension of this theorem by Konishi (1995), Laroque (2005) and Kaplow (2006) replaces the assumption of an optimal nonlinear tax system with that of the planner being able to choose any smooth function from gross to net income, and shows that an allocation with both direct and indirect taxation can always be Paretodominated by one with direct taxation alone. This in the intertemporal context again implies no taxation of the return to saving. Thus taxation of capital income is purported to be at best superfluous, at worst non-optimal.

The assumptions of weak separability, identical preferences and the existence of optimal or unrestricted nonlinear taxation are of course strong, and a number of studies ${ }^{2}$ have shown that the result, which in policy-related discussions is often expressed ${ }^{3}$ as "capital income ought to be untaxed", is not robust to their relaxation. This paper contributes to this literature by analysing the implications for the form of the optimal taxes on labour earnings and capital income of introducing household production as a form of time use, along with market work. We continue to assume identical preferences, since this avoids the issue of making interpersonal comparisons when preferences differ. ${ }^{4}$ There are strong arguments on empirical grounds for making this extension. One has only to consider typical household production activities - meal preparation, domestic accounting and financial management, laundry, house maintenance and cleaning, and above all child care - to see that they all have close but usually imperfect substitutes that can be bought on markets. ${ }^{5}$

In the next section we set out the basic two-period model of the individual consumer/worker who saves in a perfect capital market, consumes a household good and a market good in each period, and divides her time endowment between market work and household production in the first period. In Section 3 we assume there are two wage types and examine the determinants of optimal linear taxation of the return to saving when there is also optimal nonlinear taxation of labour income, given non-observability of wage types, per period consumptions and the output of household production. Section 4 concludes.

\footnotetext{
${ }^{1}$ See Atkinson and Stiglitz (1976).

${ }^{2}$ See Banks and Diamond (2010), Diamond and Saez (2011), and Boadway (2009) Ch3 for recent reviews of the literature. The present paper draws particularly on Boadway's discussion.

${ }^{3}$ See for example Mankiw et al (2009).

${ }^{4}$ In contrast to Diamond and Spinnewijn (2011) and Saez (2002) who assume preference heterogeneity across households.

${ }^{5}$ Sandmo (1990), Kleven et al. (2000), Kleven (2004) and Alesina et al (2011) analyse the issues of linear direct and/or indirect taxation in the presence of household production in an atemporal context.
} 


\section{The Individual Model}

A consumer $i$ 's utility is given by a strictly concave, increasing function

$$
u_{i}=u\left(x_{i 0}, y_{i 0}\right)+\rho u\left(x_{i 1}, y_{i 1}\right)
$$

where $x$ is a market consumption good, and $y$ is a good produced within the household. We place for the moment no a priori restrictions on the structure of within-period utilities, while adopting the standard assumption that the acrossperiod utilities are additively separable, with $\rho \in(0,1]$ a felicity discount factor. In the first period $i$ supplies market labour $l_{i}$, at a wage rate $w_{i}$ and in each period supplies $h_{i t}, t=0,1$ to household production. She retires in the second period. The time constraints, with total available time normalised at 1 , therefore are

$$
\begin{gathered}
h_{i 0}+l_{i}=1 \\
h_{i 1}=1
\end{gathered}
$$

Household production is described simply by

$$
y_{i t}=a_{i t} h_{i t}, \quad t=0,1
$$

so that the productivity coefficients $a_{i t}>0$ vary across individuals as well as over time. This variation across individuals is essentially what distinguishes time spent in household production from "leisure".

In the standard labour supply model used in analysis of optimal taxation an hour of "leisure time" produces the same implicit output for all individuals, but here one hour spent in producing the good $y$ can yield varying amounts of output, depending on the individual's type. Leisure can be defined as a household good in production of which all households have identical productivity, so that the implicit productivity coefficients can all be normalised to 1 .

The important point from the standpoint of an optimal tax model is that the $a_{i t}$ represent differences in productivities, of the same nature as the differences in wage rates $w_{i}$, rather than differences in preferences, and so present no difficulties in making interpersonal comparisons. The implicit price of a household good is its marginal opportunity cost $w_{i} / a_{i t}$, which therefore in general varies across households. If $a_{i t}>a_{j t}$ then $i$ is unambiguously better off than $j$ at any given time allocation, other things, especially wage rates, being equal.

Defining $z_{i} \equiv w_{i} l_{i}$ and assuming that each $i$ saves at the same per period interest rate $r$ in period 0 allows us to define the wealth constraint, in the absence of taxation, as

$$
\sum_{t=0}^{1} \delta^{t} x_{i t} \leq z_{i}
$$

where $\delta=(1+r)^{-1}$, and the consumer chooses optimal life time profiles of consumptions, time allocations and saving by maximising (1) subject to (2)-(5). 
In what follows however we simplify by using the household production and time constraints to write the utilities as

$$
u_{i}=u\left(x_{i 0}, a_{i 0}\left(1-\frac{z_{i}}{w_{i}}\right)\right)+\rho u\left(x_{i 1}, a_{i 1}\right)
$$

Then only the wealth constraint remains. This will of course depend on the tax system, and so we now turn to that.

\section{Optimal Linear Consumption Tax with Non- linear Income Taxation}

The planner can observe only gross labour incomes $z_{i}$ and net after-tax income, equal to the present value of consumption expenditure $c_{i}$, in period, $t=0$. There are just two wage types $i=1,2$ and we assume $w_{2}>w_{1}$. Moreover, to avoid problems of two-dimensional screening, we assume it is common knowledge that $a_{2 t}>a_{1 t}$ so that consumer 2 is unambiguously the better off of the two before taxation. Household production is unobservable and so untaxable. Producer prices are normalised at 1 in each period and without loss of generality first period consumption is chosen as the numeraire, and so indirect (capital income) taxation takes the form of a consumer price $(1+\tau)$ for second period consumption. Because of the non-observability of consumptions $x_{i t}$ only a linear $\operatorname{tax} \tau$ is feasible.

The planner's optimal tax problem can be modelled as choice of $z_{i}, \tau$ and $c_{i}$, where this last is defined by

$$
x_{i 0}+\delta(1+\tau) x_{i 1}=c_{i} \quad i=1,2
$$

Thus the planner chooses labour supply and the present value of consumption expenditure, which is equivalent to setting labour income taxation, while setting $\tau$ is equivalent to taxing the return to first period saving. The consumer maximises the utility function in (6) with $z_{i}$ given, subject to the wealth constraint in (7) with $\tau$ and $c_{i}$ also given. This yields consumption demands $x_{i t}\left(c_{i}, z_{i}, \tau\right)$, $y_{i t}\left(c_{i}, z_{i}, \tau\right)$ and indirect utility functions $V^{i}\left(c_{i}, z_{i}, \tau\right)$, with derivatives

$$
V_{c}^{i}=\lambda_{i} ; V_{z}^{i}=-a_{i 0} u_{2}^{i} / w_{i} ; V_{\tau}^{i}=-\lambda_{i} \delta x_{i 1}\left(c_{i}, z_{i}, \tau\right)
$$

where $\lambda_{i}$ is $i$ 's marginal utility of wealth.

In order to ensure satisfaction of the single crossing condition, which takes the form

$$
\frac{\partial\left[-V_{z} / V_{c}\right]}{\partial w}<0 .
$$

we assume that

$$
\frac{a_{20}}{a_{10}}<\frac{w_{2}}{w_{1}}
$$

Note also that we can maximise $u_{2}$ with $\left(c_{1}, z_{1}, \tau\right)$ as parameters, i.e. with individual 2 "mimicking" 1 , in which case we denote

$$
\hat{x}_{21}=x_{21}\left(c_{1}, z_{1}, \tau\right) ; \hat{V}^{2}=V^{2}\left(c_{1}, z_{1}, \tau\right)
$$


and with

$$
\hat{V}_{c}^{2}=\hat{\lambda}_{2} ; \hat{V}_{z}^{2}=-a_{20} u_{2}^{2} / w_{2} ; \hat{V}_{\tau}^{2}=-\hat{\lambda}_{2} \delta \hat{x}_{21}
$$

The utilitarian planner solves the problem

$$
\max _{c_{i}, z_{i}, \tau} \sum_{i} \phi_{i} V^{i}\left(c_{i}, z_{i}, \tau\right)
$$

where $\phi_{i}$ is the proportion of consumers of type $i$, subject to the government's per capita revenue constraint

$$
\sum_{i} \phi_{i}\left[z_{i}-c_{i}+\tau \delta x_{i 1}\left(c_{i}, z_{i}, \tau\right)\right] \geq G \geq 0
$$

and the incentive compatibility constraint

$$
V^{2}\left(c_{2}, z_{2}, \tau\right) \geq \hat{V}^{2}\left(c_{1}, z_{1}, \tau\right)
$$

Solving the planner's optimisation problem we obtain:

Result 1: The optimal capital income tax rate $\tau^{*}$ is given by

$$
\tau^{*}=-\frac{\mu \hat{\lambda}_{2}\left(\hat{x}_{21}-x_{11}\right)}{\lambda \sum_{i} \phi_{i} s_{i}}
$$

where $s_{i}<0$ are the compensated demand derivatives of the $x_{i 1}$ with respect to $\tau$ and $\lambda$ is the shadow price of tax revenue.

Proof: See Appendix

This result tells us that capital income should be untaxed $\left(\tau^{*}=0\right)$ if and only if $\left(\hat{x}_{21}-x_{11}\right)=0$, which will be the case if the utility function $u\left(x_{i 0}, y_{i 0},\right)$ is weakly separable in $x, y$, while future consumption should be taxed relatively more (less) heavily if $\left(\hat{x}_{21}-x_{11}\right)>(<) 0$. Thus the case for capital income taxation in this model rests on whether the higher wage consumer's second period consumption when she mimics the lower wage consumer differs from that of the latter.

In the present model the weak separability assumption is not satisfied because of the existence of the time use, household production. Whatever one may think about the common assumption of separability of consumption and leisure, to extend this to household goods and services, and especially to child care, is quite counterfactual.

Some intuition is suggested by the presence of the shadow price of the incentive compatibility constraint $\mu>0$ in (16). When $\left(\hat{x}_{21}-x_{11}\right)>0$, an increase in $\tau$ relaxes the incentive constraint by making the utility gained by the higher wage type, 2 , when she chooses $c_{1}, z_{1}$, lower relative to that she obtains when she chooses $c_{2}, z_{2}$, and this increases social welfare at the optimal type-contingent labour earnings tax levels $\left(z_{i}-c_{i}\right)$. A similar argument applies in the converse case in which $\left(\hat{x}_{21}-x_{11}\right)<0$ and $\tau$ should be reduced. When $\left(\hat{x}_{21}-x_{11}\right)=0$, the IC constraint cannot be relaxed by distorting consumer 1's allocation of $x_{1}$, the first best condition continues to be second best optimal, and only 1's labour supply needs to be distorted to relax the incentive constraint optimally. 
Thus the optimal capital income tax rate is given by a trade off between the gain in welfare it gives by relaxing the incentive constraint and the deadweight loss resulting from the distortion in optimal consumption choices, represented by the sum of compensated demand derivatives in the denominator of (16).

Note there is some similarity between this condition and that for the optimal marginal tax rate in the standard optimal linear taxation model. There, the denominator is the same while the numerator is the covariance between the marginal social utility of income across consumers and the amount of the income being taxed. The difference results from the fact that in the linear tax model, the tax rate is determined by the trade off between equity and efficiency. Here on the other hand, this role is being played by the optimal nonlinear taxes, implicitly defined by the optimal $z_{i}$ and $c_{i}$ values. The role of the indirect tax is to reduce the size of the deviation from the first best lump sum labour income taxes created by the need to ensure incentive compatibility.

At this point it is natural to enquire into the relationship between this key difference $\left(\hat{x}_{21}-x_{11}\right)$ and the substitute/complement relationships between the goods in the individuals' utility functions. The Corlett-Hague analysis ${ }^{6}$ tells us that with leisure as the untaxed good, the relative tax rate on a consumption good will be higher the stronger its complementarity with leisure, and lower the stronger its substitutability. ${ }^{7}$ In the model of intertemporal choice and the taxation of savings income however, we appear to have a contradictory result:

Result 2: The tax rate $\tau$ on savings income is relatively higher when $x_{20}$ and $y_{20}$ are Hicksian substitutes

Proof: See Appendix

This result appears to contradict the Corlett-Hague theorem, but this puzzle disappears once it is realised that the tax is being imposed on $x_{1}$, not $x_{0}$. In a reduced form sense $x_{1}$ and $x_{0}$ are gross substitutes via the wealth constraint, implying that in this sense $y_{20}$ and $x_{21}$ are complements.

The intuition for this second result is as follows. Given $c_{1}, z_{1}, w_{2}>w_{1}$ implies that if type 2 mimics type 1 , she has to work fewer hours and so has more time available for household production than if she did not mimic 1 . If the household good is a substitute for the market good consumption $x_{20}$ will be lower and therefore, given the wealth constraint, $x_{21}$ will be higher. ${ }^{8}$ Imposing a tax on $x_{1}$ then reduces the gain 2 obtains from mimicking, and so the incentive constraint is relaxed.

\footnotetext{
${ }^{6}$ See Corlett and Hague (1953).

${ }^{7}$ The paper by Kleven et al. (2000) shows in a model of linear taxation that this result no longer holds when both leisure and a consumption good produced domestically are untaxed, because the tax rates on market consumption goods will then depend on the net effect of their complementarity/substitutability relationships with the two untaxed goods. A similar result would be obtained here if we allowed many market and household consumption goods with varying substitute/complement relationships. Empirically however we would expect the substitutability relationships to dominate.

${ }^{8}$ The intertemporal structure of the model, with labour supply in the first period and taxed consumption in the second, is what causes the apparent difference to the standard CorlettHague results. But, as just pointed out, the household good at $t=0$ and consumption at $t=1$ are in a reduced form sense complements.
} 
We have a further result that shows the effect of the productivity parameter $a_{20}$ on the tax rate:

Result 3: When $x_{20}$ and $y_{20}$ are Hicksian substitutes, the higher is $a_{20}$, the higher is the tax rate $\tau$ given that it is positive and the single crossing condition is satisfied.

Proof: See Appendix

The idea here is that increasing $a_{20}$ has the same effect as increasing the wage rate, in that for given $c_{1}, z_{1}$ this increases $y_{20}$ and therefore in the substitute case reduces $x_{20}$ and increases $\hat{x}_{21}$. Note however that the single crossing condition (9) places a constraint on how high $a_{20}$ can be, as shown by (10).

\section{Conclusion}

This paper has argued that it is reasonable to introduce household production into the intertemporal model of the saving decision, and that this means that the weak separability assumption underlying the Atkinson/Stiglitz Theorem is no longer tenable. Indeed the relevant theorem for this case is the Corlett/Hague Theorem, suitably extended to recognise that current and future consumptions are gross substitutes for a given wealth constraint.

\section{Appendix}

Proof of Result 1: From the first order conditions for the problem in (13)-(15) we obtain:

$$
\begin{gathered}
\lambda \phi_{1}=\lambda_{1} \phi_{1}-\mu \hat{\lambda}_{2}+\lambda \phi_{1} \tau^{*} \delta \frac{\partial x_{11}}{\partial c_{1}} \\
\lambda \phi_{2}=\lambda_{2} \phi_{2}+\mu \lambda_{2}+\lambda \phi_{2} \tau^{*} \delta \frac{\partial x_{21}}{\partial c_{2}} \\
-\sum \lambda_{i} \phi_{i}+\lambda \delta \sum \phi_{i}\left(x_{i 1}+\tau^{*} \frac{\partial x_{i 1}}{\partial p}\right)+\mu\left(V_{p}^{2}-\hat{V}_{p}^{2}\right)=0
\end{gathered}
$$

Substituting from (17) and (18) into (19) and using the Slutsky equations $\partial x_{i 1} / \partial \tau=s_{i}-\delta x_{i 1} \partial x_{i 1} / \partial c_{i}$ gives the result.

Proof of Result 2: Given $c_{1}, z_{1}, \tau, a_{1 t}$ and $w_{1}$, the type 1 consumer chooses $x_{11}$. Then ceteris paribus $\tau$ is higher the greater is the difference $\left(\hat{x}_{21}-x_{11}\right)$. Thus we just have to carry out the standard comparative statics analysis of the effect of an increase in 2's wage on her equilibrium choice $\hat{x}_{21}$ when she mimics 1. Standard comparative statics shows that

$$
\frac{\partial \hat{x}_{21}}{\partial w_{2}}=-u_{120} \frac{a_{20} z_{1} \delta\left(1+\tau^{*}\right)}{D w_{2}^{2}}
$$


where $u_{120} \equiv \partial^{2} u / \partial y_{20} \partial x_{20}$ and $D>0$. Thus if $x_{20}$ and $y_{20}$ are substitutes $u_{120}<0$ and $\partial \hat{x}_{21} / \partial w>0$ and therefore $w_{2}>w_{1} \Rightarrow \hat{x}_{21}>x_{11}$. In that case $\tau^{*}>0$ and, other things equal, will increase with $w_{2}$.

Proof of Result 3: Carrying out the same standard comparative statics analysis as in Result 2 we obtain

$$
\frac{\partial \hat{x}_{21}}{\partial a_{20}}=-u_{120} \frac{a_{20} \delta\left(1+\tau^{*}\right)\left(1-z_{1} / w_{2}\right)}{D}
$$

and the same argument as used there applies.

\section{References}

[1] Alesina, A, A Ichino and L Karabarbounis (2011), "Gender Based Taxation and the Division of Family Chores". American Economic Journal: Economic Policy, 3(2),1-40.

[2] Apps, P and R Rees (2009), Public Economics and the Household, Cambridge: Cambridge University Press.

[3] Atkinson, A, and J Stiglitz (1976), "The Design of Tax Structure: Direct vs Indirect Taxation", Journal of Public Economics, 61(1-2), 55-75.

[4] Banks, J, and P Diamond (2010),"The Base for Direct Taxation", in Mirrlees et. al., (2010), Dimensions of Tax Design, Oxford University Press.

[5] Boadway, R (2012), From Optimal Tax Theory to Tax Policy, MIT Press

[6] Corlett, W, and D Hague (1953), "Complementarity and the Excess Burden of Taxation", Review of Economic Studies, 21 (1), 21-30.

[7] Diamond, P, and E Saez (2011), "The Case for a Progressive Tax: From Basic Research to Policy Recommendations". Journal of Economic Perspectives, 25(4), 165-190.

[8] Diamond P, and J Spinnewijn (2011), "Capital Income Taxes with Heterogeneous Discount Rates", American Economic Journal: Economic Policy, $3(4), 52-76$.

[9] Kaplow, L (2006), "On the Desirability of Commodity Taxation Even When Income Taxation is Not Optimal", Journal of Public Economics, 90(6-7), 1235-90.

[10] Kleven, H, W Richter and P Sørensen (2000), "Optimal Taxation with Household Production", Oxford Economic Papers, 52(3), 584-594 
[11] Konishi, H (1995), "A Pareto-Improving Commodity Tax Reform Under a Smooth Nonlinear Income Tax", Journal of Public Economics, 56(3), $413-46$.

[12] Laroque, G (2005), "Indirect Taxation is Superfluous under Separability and Taste Homogeneity: A Simple Proof", Economics Letters, 87(1), 141144.

[13] Mankiw, N, M Weinzierl and D Yagan (2009), "Optimal Taxation in Theory and Practice", Journal of Economic Perspectives, 23(4), 147-174.

[14] Mirrlees, J, S Adam, T Besley, R Blundell, S Bond, R Chote, M Gammie, P Johnson, G Myles, J Poterba (2010), Dimensions of Tax Design, Oxford University Press.

[15] Saez, E (2002), The Desirability of Commodity Taxation under Nonlinear Income Taxation and Heterogeneous Tastes", Journal of Public Economics, 83(2), 217-230.

[16] Sandmo, A (1990), Tax distortions and household production. Oxford Economic Papers, 42(1), 78-90. 